\title{
Resenha do livro Desemprego: uma abordagem psicossocial
}

\author{
Laerte Idal Sznelwar ${ }^{1}$ \\ Professor associado \\ Departamento de Engenharia de Produção \\ Escola Politécnica Universidade de São Paulo
}

A leitura do livro Desemprego: uma abordagem psicossocial, de Belinda Mandelbaum e Marcelo Ribeiro, se inscreve numa perspectiva de discutir um grave problema relacionado ao sistema econômico e às escolhas políticas feitas pelas mais diferentes sociedades. Qual é a quantidade de pessoas que terão emprego? Entre elas, quantas estarão empregadas por um longo período? A quem serve essa quantidade de pessoas desempregadas que são mais ou menos formalmente qualificadas para desempenhar papéis que interessam àqueles que têm poder para decidir que tipo de trabalho e emprego será oferecido à população? Será que tudo é planejado e fruto do desejo daqueles que possuem esse poder? A organização da própria sociedade e da economia tem uma parte que não é passível de controle?

O livro não trata diretamente dessas questões, mas permite que as coloquemos como reflexões no que diz respeito ao futuro das sociedades e da cultura; no caso específico do Brasil, como se poderá pensar em cenários em que os cidadãos poderão viver tendo como horizonte a possibilidade de se desenvolver profissionalmente, se realizar enquanto sujeitos e contribuírem para o desenvolvimento das relações sociais e da cultura, de um modo mais amplo e significativo.

A proposta dos autores é voltada para dar voz àqueles que perderam espaço na sociedade, que perderam seu emprego e que estão numa busca incessante para reconquistar uma posição que lhes permita, ao menos, sobreviver. Entretanto, durante a leitura fica evidente que a questão é muito mais profunda, pois não se trata de ter um emprego apenas, mas sim a própria possibilidade da existência enquanto sujeito que está em perigo. Também podemos colocar em questão qual era o lugar na sociedade que esses sujeitos tinham antes de ficarem desempregados, se aquilo que exerciam como papel era considerado relevante pelos outros e por si mesmos.

Quase que inexoravelmente, nos exemplos apresentados fica claro que a vivência do "não ter mais" questiona muito mais do que a relação entre capital e trabalho. O que está em perigo, como dito, é a identidade das pessoas, a vida conjugal e familiar, a vida em sociedade. Há uma evidente perda dos espaços na vida que permitem reforçar os processos de subjetivação, uma vez que, ao viver recolhido, o sujeito perderia as possibilidades de ter, de alguma maneira, reconhecido seu papel social. Haveria um grande risco de encolhimento, de perda na sua capacidade de agir em todos os campos da sua vida.

As críticas feitas a uma sociedade pautada na exacerbação da competição, de uma busca obsessiva por uma produtividade que permitiria às empresas continuarem no mercado, são muito importantes. Indo ainda mais nesse sentido, fica mais notório que muito o que se apregoa como sendo um determinismo, diante do qual nada se pode fazer, a não ser entrar no jogo, faz parte de uma ideologia. Ideologia que refuta a ideologia. Esse paradoxo, ou melhor, esse eufemismo é parte integrante do que os defensores do neoliberalismo repetem ininterruptamente. Dizem que nada há de ideológico e que eles apenas fazem e constroem uma sociedade mais justa, porque evita desperdícios

1 Médico pela Faculdade de Ciências Médicas da Unicamp, doutor em ergonomia e pós-doutorado em psicodinâmica do trabalho pelo Laboratoire d'Ergonomie et Neurophysiologie du Travail do CNAM, livre-docente em engenharia de produção pelo Departamento de Engenharia de Produção da Escola Politécnica da USP. 
e faz o melhor que se pode, sem entrar em debates ideológicos. É estarrecedor esse tipo de posição, uma vez que nada pode ser considerado a-ideológico, há sempre ideias que apoiam e baseiam qualquer tipo de processo decisório. O que se passa nas empresas e nas instituições públicas é uma construção de modos de gestão e de organização do trabalho centrados no ideário neoliberal.

Como bem apresentado nesse livro, esse ideário apregoa que todos os sujeitos devem se manter empregáveis, que cada um seja suficientemente sedutor e objeto do desejo das empresas para que possam ser prontamente chamados quando houver trabalho. Cabe a cada um manter o seu portfólio em dia para que não perca as chances de continuar no caminho de idas e vindas "próprio" ao mercado de trabalho e, assim, a sua vida profissional terá continuidade. O mais intrigante de tudo isso é que esse tipo de ideologia não é necessariamente contrário às aspirações humanas. Todos estão em busca de um lugar ao sol, de serem reconhecidos pelos outros e de terem a liberdade de escolher o que querem fazer e, consequentemente, ser. O problema é saber se esse tipo de captura da subjetividade está a serviço de processos de liberação e de emancipação dos humanos ou, de fato, é um processo de dominação ainda mais perverso que os anteriores, sobretudo quando fazemos uma comparação com o capitalismo industrial do início do século XX, para o qual o que interessava era apenas o aprimoramento da força e de certas habilidades dos sujeitos trabalhadores, deixando de lado a sua inteligência e subjetividade.

Esses processos eufemísticos de reforço do sujeito individual constituem cenários propícios para a sua destruição, uma vez que, por meio deles, com a ilusão de um reforço egoico, o que está se propiciando é o aumento substantivo da competição de todos contra todos; incluindo luta de si contra si próprio. Diferentes atores citados no livro tratam, à sua maneira, essa questão. Arendt coloca em evidência a perspectiva da criação de cenários desoladores; Dejours os discute enfocando o sofrimento patogênico.

Parte desses cenários desoladores e patogênicos está relacionada com essa perda de solidariedade e com o esfacelamento dos coletivos. Se aquilo que prevalece nos modelos de avaliação de desempenho nas empresas, o que é reproduzido também nos processos de escolarização, é feito em detrimento do coletivo e da vida em comum, que tipo de sociedade estamos criando? Alguns poderiam argumentar no sentido de que aquilo que ocorre nas empresas não está ligado à vida no exterior de suas paredes, como se esta pudesse ser independente daquilo que se faz no trabalho, como se a vida no trabalho não modulasse os sujeitos e a sociedade de um modo mais amplo. A tese da centralidade do trabalho vale para todos, para os que tem e para os que perderam seus empregos.

Essa passagem sobre as empresas traz uma questão importante. Se o trabalho, enquanto temos emprego, é um processo que reforça a alienação (alienação que não diz respeito apenas à possessão dos meios de produção, mas aos mecanismos psíquicos de defesa), temos que tentar fazer uma relação entre a vivência dos sujeitos empregados e aqueles que perderem o emprego.

No livro, por meio dos exemplos dados, fica evidente que os sujeitos desempregados estão cada vez mais sós, e que a solidariedade adviria principalmente das relações com a família e os amigos, relações que se tornam cada vez mais problemáticas, até porque os outros começam a se defender acusando o desempregado pela falta do emprego. Não se trata aqui de enfatizar os processos de vitimização, uma vez que eles serviriam para reforçar relações servis e alienadas. A questão é mais de colocar em debate como os processos de alienação, para dar conta de tarefas sem sentido, alienantes e sob forte concorrência, reforçariam a fragilização dos sujeitos, algo que reduziria as possibilidades de haver processos reflexivos tanto individuais e coletivos para se construir modalidades não apenas de resistência, como também favorecer novas formas de agir e de existir.

Outra reflexão que o texto de Belinda Mandelbaum e Marcelo Ribeiro nos propicia diz respeito à intensificação dos processos de precarização do trabalho. Essa questão, que faz parte da vida de muitos desde há muito, se torna cada vez mais a regra. No mundo do sujeito neoliberal, a ideia de permanência é algo a ser superado, as relações se tornam mais frágeis e as pessoas podem ser trocadas, ao menos em princípio, com mais facilidade. Esse cenário é ainda reforçado por aqueles que, por algum 
motivo, em geral ligado às condições e à organização do trabalho, perderam, em parte ou totalmente, a possibilidade de agir no mundo, em específico no mundo da produção.

Fica também evidente à leitura do livro que há um aumento significativo das relações de dependência, seja das instituições de seguridade social e/ou da família. Essa perda da relativa autonomia conquistada pela entrada no mercado de trabalho condiz com os testemunhos apresentados e com o profundo sofrimento que a perda do sentimento de utilidade trazem. Como ser alguém mais autônomo, buscando um caminho em direção da realização de si, do desenvolvimento dos coletivos e da cultura, em cenários de reforço da dependência? Isso ilustra mais uma das falsidades do eufemismo da individualização; em vez de reforçar o sujeito, o torna dependente, como se houvesse um retorno ao período de sua infância, sem jamais sê-lo.

Reiterando o que podemos ter como horizonte, tendo em vista os pressupostos da psicodinâmica do trabalho, há que se considerar que tipo de trabalho é proposto para as pessoas. De que maneira, por meio do trabalho, estamos nos desenvolvendo e trilhando caminhos emancipatórios. Ao que me parece, as políticas que reforçam o desemprego, como bem ilustrado no livro, são coerentes com um trabalho sem qualidade. As pessoas já vivenciam, quando tem um emprego, uma situação que reforça a alienação, a submissão. Como mudar esses cenários é um grande desafio para todos e para a sociedade, não podemos esquecer que aquilo que ocorre aos outros tem influência sobre todos, sobre nós mesmos.

Portanto um dos possíveis caminhos que esse livro nos abre é o de discutir profundamente a questão da divisão do trabalho remunerado, em especial quando colocamos em perspectiva a miríade de atividades humanas que não são consideradas como trabalho por não serem remunerados. De qualquer maneira, aquilo que é remunerado e aquilo que não o é não necessariamente definem o que é o trabalho, principalmente aquele que fazemos sobre nós mesmos ao nos confrontarmos com a realidade ao desenvolver nossas atividades, o trabalho sobre si, o arbeit para Freud. Mesmo que não fique claro a um primeiro olhar, qualquer atividade é relacional, seja porque estamos diretamente interagindo com outrem, e porque esse outrem faz parte do nosso universo psíquico.

Será que chegamos a um momento na sociedade no qual será necessário desvincular o trabalho do capital? As propostas de renda universal precisam ser analisadas com profundidade, uma vez que, em princípio, propiciam um cenário favorável a desvincular sobrevivência de cada um daquilo que é imposto pelas empresas. Será que assim poderemos desenvolver atividades mais interessantes, negando atividades monótonas, repetitivas e sem sentido? Será que poderemos nos desenvolver profissionalmente mesmo não tendo um vínculo formal com uma determinada instituição ou empresa, mas sim um laço forte com a profissão, por meio de diferentes dispositivos e institucionalizações a serem pensados, criados ou ainda recriados? Os vínculos com a profissão e os coletivos não dependeriam mais de uma relação direta com o emprego, mas com o existir naquela profissão, desenvolvendo atividades que se inscrevam no tempo. Será possível?

A leitura do livro Desemprego: uma abordagem psicossocial permite e induz a um aprofundamento das nossas reflexões sobre como construir caminhos pautados em ações no âmbito da política, no sentido do agir individual e coletivo na pólis.

\section{Referência}

Mandelbaum, B. \& Ribeiro, M. A. (2017). Desemprego: uma abordagem psicossocial. São Paulo: Blucher.

\section{Endereço para correspondência}

laertesz@usp.br
Enviado em: 03/10/2017

Revisado em: 02/11/2017

Aprovado em: 03/11/2017 